\title{
Resin-bonded Bridges: Survival and Recent Concept
}

\author{
Sunil K Mishra ${ }^{1}$, Ramesh Chowdhary ${ }^{2}$ \\ International Journal of Prosthodontics and Restorative Dentistry (2020): 10.5005/jp-journals-10019-1282
}

Resin-bonded bridges (RBBs) were first described in 1970s and gradually gained acceptance by clinicians as an alternative fixed restorative treatment option for the replacement of a missing tooth. Rochette in 1973 was the first person to describe the design feature of these prostheses. ${ }^{1}$ The main advantage of RBBs is the fixed restoration of missing teeth with conservative preparation of abutment teeth. The dissolution of the exposed cement was one of the main disadvantages of the perforated retainers which causes leakage underneath the retainers and debonding of the restoration. Due to tremendous development in preparation designs and bonding techniques of RBBs, the success rate of these bridges enhanced in recent years. ${ }^{2}$

Balasubramaniam had done a systematic review to evaluate the survival rate of RBBs and found that survival rate in 5 years of follow-up to be $83.6 \%$ and in 10 years as $64.9 \%$. The most common type of failure found was the debonding of the prosthesis. Resinbonded bridges placed in the anterior region were found to be more retentive than posteriors and RBBs in the maxilla were found to be more retentive than bridges placed in the mandible. ${ }^{3}$ Alraheam et al. had compared RBBs fabricated from different materials in their systematic review. In 5 years of follow-up, they found a success rate of $88.18 \%$ for the metal framework RBBs and $84.41 \%$ for the nonmetal framework RBBs. Debonding of the framework and fracture of the retainer of the adhesive frameworks were the main technical complications reported in the studies, 82 and $15 \%$, respectively. ${ }^{2}$

For several years, all-ceramic RBBs have been considered an esthetic treatment option for the replacement of missing teeth in the anterior region. With continued developments in technology, various ceramic materials have been used to fabricate all-ceramic RBBs including zirconia, glass-reinforced, alumina-based ceramics, and lithium disilicate glass-ceramics. Shahdad et al. evaluated the clinical longevity of 58 adhesively bonded single unit yttriastabilized tetragonal zirconia polycrystalline (Y-TZP) ceramic cantilever RBBs. Forty-eight restorations remain in service with a survival rate of $82.7 \%$ in a mean follow-up of 36.2 months. ${ }^{4}$

Thoma et al. in their systematic review assessed the 5- and 10-year survival of RBBs. They found a survival rate of $86.7-94.4 \%$ after 5 years and $82.9 \%$ after 10 years. A significantly higher survival rate was reported for RBBs with the zirconia framework compared with RBBs from other materials. For metal-ceramic RBBs, the annual debonding rate was $2.89 \%$, for metal-acrylic, it was $4.17 \%$, for fiberreinforced composite RBBs, it was $1.72 \%$, and for zirconia framework RBBs, it was $1.42 \%$. Resin-bonded bridges with one retainer had a significantly higher survival rate and a lower debonding rate compared with RBBs retained by two or more retainers. ${ }^{5}$ In another systematic review, Tezulas et al. also found that cantilever design
${ }^{1}$ Department of Prosthodontics and Crown and Bridge, Rama Dental College and Hospital and Research Centre, Kanpur, Uttar Pradesh, India ${ }^{2}$ Department of Prosthodontics and Crown and Bridge, RajaRajeswari Dental College and Hospital, Bengaluru, Karnataka, India

Corresponding Author: Sunil K Mishra, Department of Prosthodontics and Crown and Bridge, Rama Dental College and Hospital and Research Centre, Kanpur, Uttar Pradesh, India, Phone: +91 7697738478, e-mail: sunilmsr200@yahoo.co.in

How to cite this article: Mishra SK, Chowdhary R. Resin-bonded Bridges: Survival and Recent Concept. Int J Prosthodont Restor Dent 2020;10(3):93.

Source of support: Nil

Conflict of interest: None

all-ceramic RBBs are more successful than the two-retainer design in the anterior region. ${ }^{6}$

Although RBBs is considered to be a minimally invasive treatment option compared with a conventional fixed dental prosthesis but technical complications such as debonding is still frequent. Recent research favored all-ceramic anterior RBBs with a single-retainer design. Application of RBBs in the posterior region of the jaws needs further research with newer materials and techniques for improved treatment outcomes.

\section{References}

1. Rochette AL. Attachment of a splint to enamel of lower anterior teeth. J Prosthet Dent 1973;304(4):418-423. DOI: 10.1016/00223913(73)90163-7.

2. Alraheam IA, Ngoc CN, Wiesen $C A$, et al. Five-year success rate of resin-bonded fixed partial dentures: a systematic review. J Esthet Restor Dent 2019;31(1):40-50. DOI: 10.1111/jerd.12431.

3. Balasubramaniam GR. Predictability of resin bonded bridges - a systematic review. Br Dent J 2017;22(11):849-858. DOI: 10.1038/ sj.bdj.2017.497.

4. Shahdad S, Cattell MJ, Cano-Ruiz J, et al. Clinical evaluation of all ceramic zirconia framework resin bonded bridges. Eur J Prosthodont Restor Dent 2018;26(4):203-211. DOI: 10.1922/ EJPRD_01810Shahdad09.

5. Thoma DS, Sailer I, loannidis A, et al. A systematic review of the survival and complication rates of resin-bonded fixed dental prostheses after a mean observation period of at least 5 years. Clin Oral Impl Res 2017;28(11):1421-1432. DOI: 10.1111/clr.13007.

6. Tezulas E, Yildiz C, Evren B. Clinical procedures, designs, and survival rates of all-ceramic resin-bonded fixed dental prostheses in the anterior region: a systematic review. J Esthet Restor Dent 2018;30(4):307-318. DOI: 10.1111/jerd.12389.

(c) Jaypee Brothers Medical Publishers. 2020 Open Access This article is distributed under the terms of the Creative Commons Attribution 4.0 International License (https://creativecommons.org/licenses/by-nc/4.0/), which permits unrestricted use, distribution, and non-commercial reproduction in any medium, provided you give appropriate credit to the original author(s) and the source, provide a link to the Creative Commons license, and indicate if changes were made. The Creative Commons Public Domain Dedication waiver (http://creativecommons.org/publicdomain/zero/1.0/) applies to the data made available in this article, unless otherwise stated. 